\title{
Hematidrosis (bloody sweat): a review of the recent literature (1996-2016)
}

\author{
Nicolas Kluger ${ }^{1 凶}$
}

\begin{abstract}
Hematidrosis is an eccrine sweat disorder characterized by one or more episodes of spontaneous, bloody sweating from nontraumatized skin. The author carried out a systematic review of all cases of hematidrosis reported in PubMed over the past 20 years. A total of 25 cases were reviewed; 21 were women ( $84 \%$ ), the median age was 13 years (range 9-72), and the majority (62\%) were from Asia, mainly India. Hematidrosis was located on the face-including the forehead ( $40 \%)$, eyes ( $40 \%)$, and ears ( $36 \%)-$ in $96 \%$ of the cases and on the umbilicus in $24 \%$ and the palms in $20 \%$. Prodromal symptoms were reported by almost $30 \%$ of the patients. Possible triggering factors were identified in $56 \%$ of the cases; most of these (86\%) were stress factors within families (conflicts or abuse) or at school. In two cases, platelet dysfunction and epilepsy were suspected as culprits. Nine patients had a psychiatric diagnosis associated with hematidrosis. The outcome was favorable in most of the cases with medical treatment (e.g., beta-blocker, anxiolytics) and psychological support. The number of cases has increased in recent years. Hematidrosis appears to be a somatization disorder that mainly affects children from developing countries. Its physiopathology remains largely unknown. It deserves better recognition because it is usually a temporary condition when managed properly.
\end{abstract}

Keywords: hematidrosis, hematohidrosis, blood, sweat glands, bloody sweat, bleeding, somatization, stress

Received: 16 October 2017 | Returned for modification: 22 October 2017 | Accepted: 19 November 2017

\section{Introduction}

Hematidrosis (ICD 102016 diagnosis code L74.8) is an eccrine sweat disorder presenting as one or several episodes of spontaneous, bloody sweating from non-traumatized skin (1). It is an extremely rare and remarkable phenomenon. According to the New Testament (Luke 22:44), Jesus Christ presented symptoms in the garden of Gethsemane before his arrest. This biblical episode adds a mystical perspective to this condition. Therefore, it is not surprising that some cases of hematidrosis in pious environments have been misinterpreted as religious stigmata (2). In 1996 Holoubek and Holoubek performed a comprehensive review of 76 prior cases of bloody sweat (3). However, the authenticity of many reports has been questioned because diagnoses were made clinically without laboratory investigations. Hematidrosis remains an elimination diagnosis, made after ruling out other conditions such as bleeding disorders, chromhidrosis, or self-inflicted skin lesions $(1,4)$. Because the number of case reports in the literature has increased over the past 20 years, the author took the opportunity to review the cases of hematidrosis that have been reported since Holoubek and Holoubek's review (3).

\section{Methods}

The author carried out a PubMed search for December 1996 through December 2016 using the following keywords: hematidrosis, haematidrosis, hematohidrosis, haematohidrosis, and hemotidrosis. The search included no other restrictions and produced 27 related articles. One was an earlier review by the author of this review (1) and another was a letter of response to that review (5). Two cases were excluded from the current review because the articles were written in Chinese $(6,7)$. The 23 remaining articles are included in this review, which analyzes the cases for demographic data, the location of hematidrosis on the body, the occurrence of prodromal symptoms, the recorded sample analyses such as cytology, biochemistry, or a simple coloring reaction like a benzidine test, the presence of a physician or a nurse during at least one episode of hematidrosis, clinical pictures in the articles, the identification of comorbidities and precipitating factors, treatments, and outcomes.

\section{Results}

A total of 25 cases were reviewed, 21 of which $(84 \%)$ were in women (8-30). Only eight patients (32\%) were adults at the time of diagnosis, and the median age was 13 years (range 9-72). The patient characteristics are summarized in Table 1 . The patient's country of origin was available for 24 patients (Fig. 1). Fifteen $(62 \%)$ were from Asia, including $10(42 \%)$ from India or Pakistan. Six (25\%) were from Africa-either Maghreb or South Africa-and only one (4\%) was from Europe. The case of this patient, from Spain, was published in two separate reports $(16,17)$.

The median time between the onset of symptoms and the first consultation was 6 months, with a range of a few days to 6 years. Hematidrosis was located mainly on the face in 24 cases (96\%), including the forehead in 10 cases $(40 \%)$. Eyes and ears were affected in $10(40 \%)$ and nine (36\%) cases, respectively. The umbilicus was mentioned specifically in six cases (24\%), the palms in five cases $(20 \%)$, and the soles in two cases $(8 \%)$. The localizations are summarized in Fig. 2. Seven patients (28\%) reported either prodromal general symptoms (headaches, abdominal pain, nausea, or vomiting) or prodromal local sensations (tingling or soreness). Mucosal bleeding, such as epistaxis or bleeding from other mucosae-usually restricted to one mucosa-was reported in eight patients. Bleeding in the mouth was reported three times; bleeding on the tongue was reported twice. Bleeding from multiple 
mucosae was reported in two patients $(12,23)$, one of whom was found to have a platelet function defect (Platelet Factor 3, PF3 dysfunction) (12). An analysis of the bloody secretions was performed in 18 cases $(72 \%)$, in two instances indirectly on clothes or tissues $(11,22)$. Healthcare providers witnessed spontaneous episodes of bleeding in 16 patients (64\%). Family members witnessed bleeding in one of these cases. In the other nine cases, spontaneous bleeding was either not assessed or not clearly explained in the article. One or more photos depicting a bleeding episode were available in 17 articles (68\%). Skin biopsies were performed in nine cases (36\%). Other than the initial observation by Maronukul et al. (8), who reported blood-filled spaces opened in the follicular canals, all of the biopsies were unremarkable or showed only minimal or inconsistent changes.

Possible triggering factors were identified in 14 cases (56\%). In 12 of these (86\%), triggers were identified as stress factors within families, such as conflicts or abuse, or at work or school. Some very traumatizing and violent episodes were mentioned, such as witnessing the beheading of a woman (10) or the abduction of a sister (15). Organic triggering factors were reported in two cases: trauma on the forehead in one case (30) and seizures in the other (24). A psychiatric diagnosis was associated with hematidrosis in nine patients, including anxiety, depression, conversion disorder, and oppositional defiant disorder. One patient was described as having an IQ under 70.

Information about the management of hematidrosis was available for 20 patients $(80 \%)$. Oral treatments included mainly beta blockers $(45 \%)$ anxiolytic drugs $(30 \%)$, and sometimes antidepressants $(10 \%)$. Local treatments, such as atropine patches or drops of adrenalin applied with gauze, were rarely given. Psychotherapy, counseling, or relaxation therapies were given to seven patients (35\%), either alone or in association with pharmacological treatments. In two cases $(10 \%)$ no treatment was given.

The outcomes for five patients were not described in the articles, and two other patients were lost to follow-up. Improvement or full healing was reported in the remaining 18 cases. In 13 cases $(72 \%)$, healing occurred from a few days to 12 months after onset. In two cases (11\%), relapses occurred after stopping beta blockers. In two other cases, remission was spontaneous without any medical intervention.

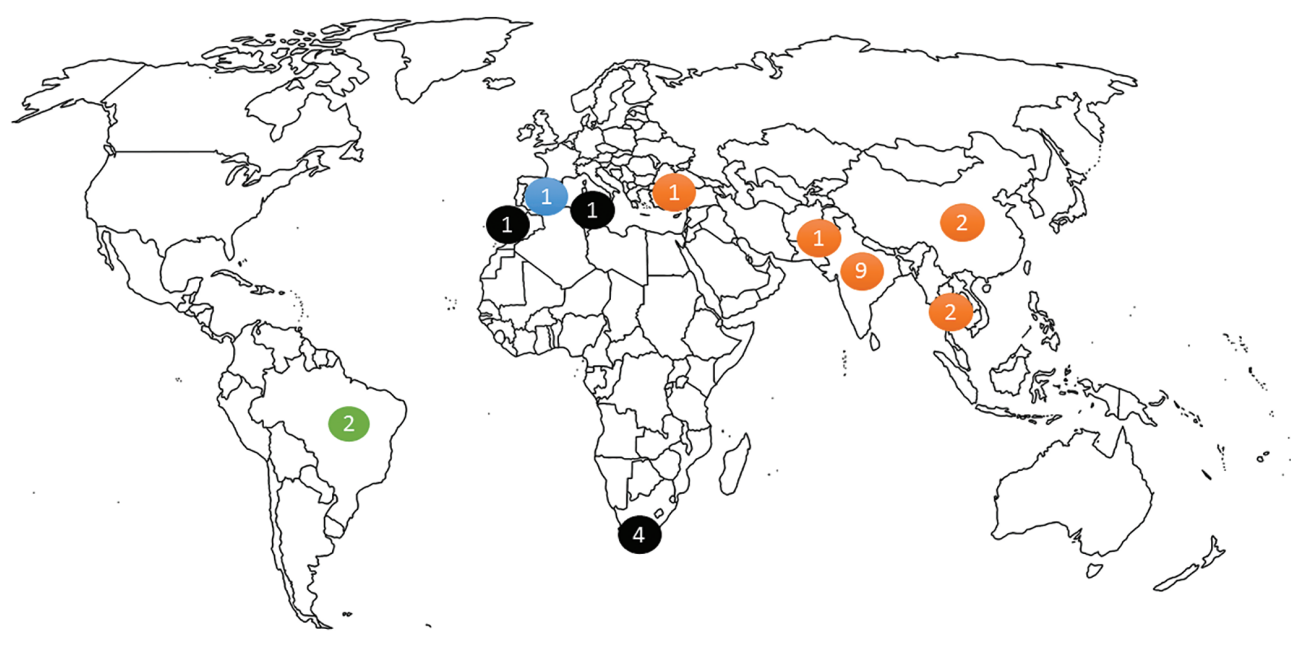

Figure 1 | Worldwide distribution of 24 cases of hematidrosis.

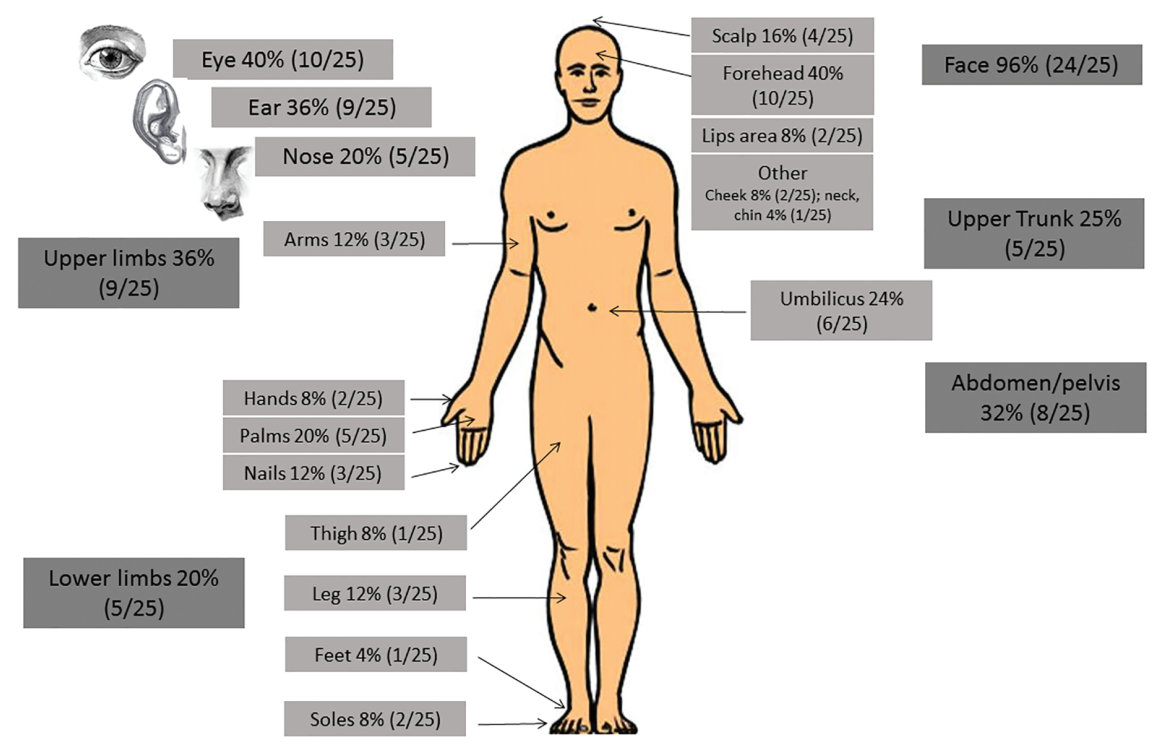

Figure 2 | Localization of hematidrosis in 25 patients. 


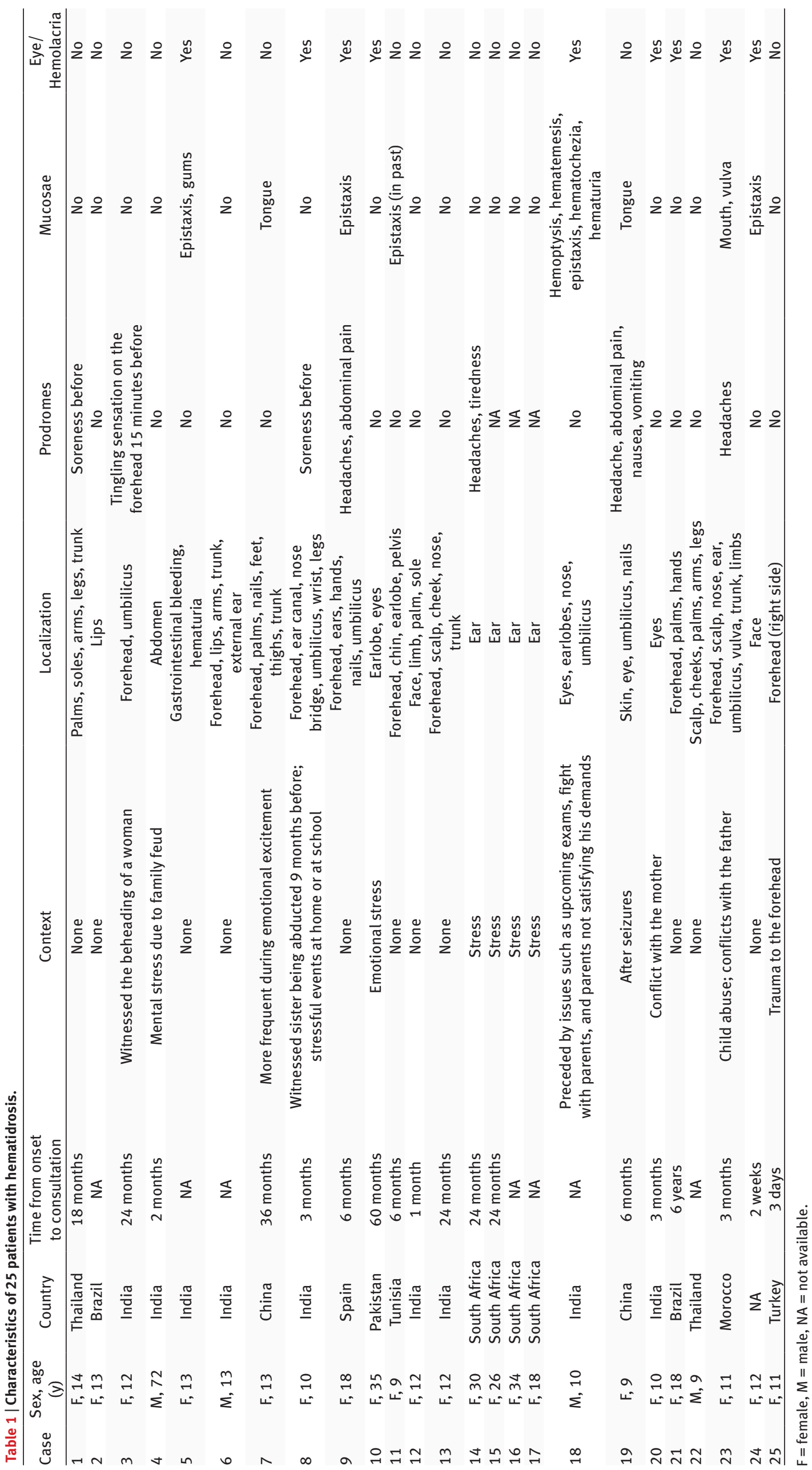




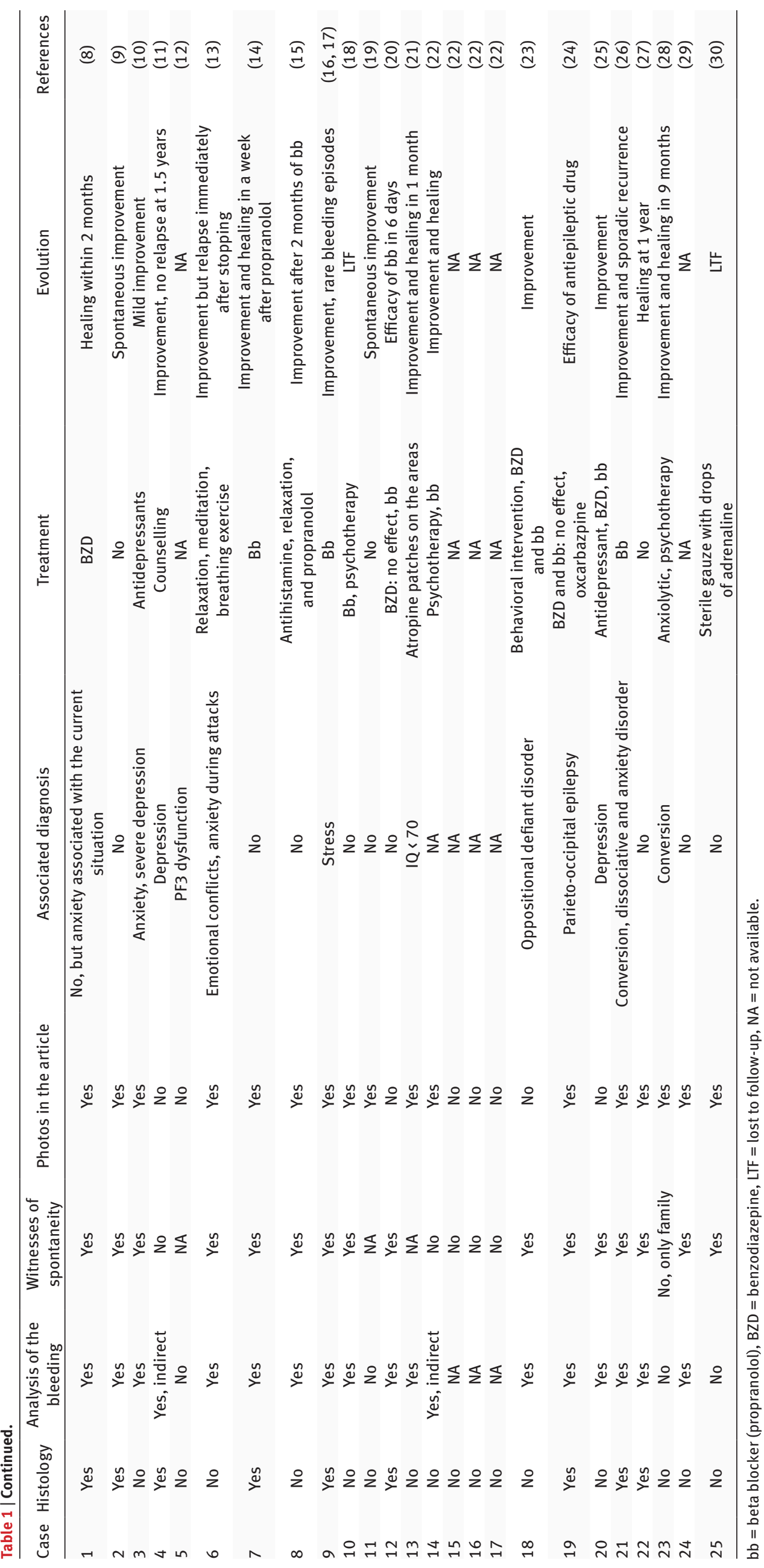




\section{Discussion}

This review covers the most recent cases of hematidrosis that have been reported since 1996. Hematidrosis is a rare and fascinating condition, the prevalence and incidence of which are still unknown. It is notoriously rare, as illustrated by the almost complete absence of case series except for a series of four patients with ear bleeding (22). The number of reported cases of hematidrosis has increased over the past 20 years. In fact, it is important to stress that a large majority of the cases that were reviewed by Holoubek and Holoubek in 1996 were cases originating in the 19th century or earlier (3). They found only six cases of "psychogenic stigmatization" or "vicarious menstruations" that occurred between 1957 and 1980. The most recent case in their review was reported in 1980 (6).

Most of the cases reviewed here displayed a "stereotypical" presentation. Hematidrosis mainly affects young girls between the ages of 9 and 15. It can occur on any part of the body from scalp to toes, but mainly affects the face (especially the forehead), the upper limbs (palms), and the umbilicus. The number of episodes per day varied among the cases reviewed here and, even though hematidrosis is said not to occur during sleep, some mentioned episodes during the night. More than one-fourth of the patients could forecast the episodes by local or general prodromal symptoms. Clinically, bleeding presented as the sweating of a pink liquid that was clearer and more fluid than blood (8-30).

Biochemical analysis shows that hemoglobin is at lower concentrations in bloody sweat than in venous blood $(8,27)$. In some of the cases in this review, cytology or coloring reagents confirmed the presence of blood in the sweat. In this context, the authenticity of the case reported by Rharrabti et al. can be debated. They reported a child with "sticky" bloody fluid, but without any laboratory analysis or the presence of medical staff during a spontaneous episode (28). In all cases reviewed here the progression was favorable, ranging from mild improvement to complete healing. Management with psychotherapy, anxiolytic drugs, or beta blockers proved to be effective in almost all cases.

This review sheds light on some interesting aspects. It is rather striking that almost half of the cases originated in India, and more broadly in Asia (Fig. 2). Reported cases in Europe and North America, on the other hand, are almost nonexistent. There is no explanation for such distribution, although a genetic predisposition could explain the current geographical distribution of hematidrosis. Social and cultural background also could play a role in the occurrence of hematidrosis, especially because this condition can be seen as a somatization disorder. Interestingly, despite the remarkable nature of the cases, at no point do the reports mention any excessively religious interpretation of the symptoms. Severe emotional stress can trigger hematidrosis, such as the fear of death (like in the account in the Bible), witnessing a violent death, or the abduction of a relative. However, even school exams or family conflicts seem sufficient to trigger bloody sweats. Furthermore, in half of the cases, no triggering factor was identified.

Another surprising aspect is that some patients reported epistaxis, oral bleeding, intestinal bleeding, or hematuria. There was no clear explanation for such bleeding, and all but one report failed to find any bleeding disorders. One Indian patient was diagnosed with $\mathrm{PF}_{3}$ dysfunction (12) with prothrombin time, activated partial thromboplastin, thrombin time, and bleeding time within normal ranges. As emphasized by a recent Indian study, $75 \%$ of patients with mild bleeding remain undiagnosed even after extensive laboratory workup (32). To date, hematidrosis has not been connected to any bleeding disorder. It is also difficult to believe that an organic bleeding disorder would resolve spontaneously or under propranolol or psychotherapy. It is advisable to perform broad investigations when hematidrosis is associated with other bleeding symptoms or in cases of protracted progression.

This review has several limitations. The selected articles were all from PubMed and written only in English or French. Two cases reports written in Chinese were excluded, for example. The review focuses only on cases that were identified as hematidrosis by the reports' authors, and additional cases that were formulated differently in an article or were misdiagnosed may have been missed. The use of various spellings provides too many possible entries for such a rare condition: $h(a)$ ematidrosis, $h$ (a)ematohidrosis, or simply bloody sweat. Manonukul et al. even suggested the term hematofolliculohidrosis (8). Only one term should be used in order to avoid confusion and data dispersal. The 1oth Revision of the WHO's International Statistical Classification of Diseases and Related Health Problems (ICD 10) recognizes only one entry: hematidrosis (31). Periorificial bleeding has been described in vague ways in the reports: nose bleeding can be interpreted either as epistaxis or as bleeding from the bridge of the nose, ear bleeding can refer to bleeding from the earlobe or from the ear canal, and eye bleeding can refer to hemolacria (tears of blood) or to bleeding from the eyelid. Rouxel et al. reported the case of an 11-yearold French girl that presented with transient bleeding from the eyelids. The bloody nature of the secretions was confirmed. She had had problems at school and a history of sexual molestation when she was 4. Depressive and suicidal thoughts with periods of anxiety coincided with the bleeding. The symptoms stopped during hospitalization in a pediatric psychiatry unit. Rouxel et al. suggested a diagnosis of self-inflicted skin disorder (dermatitis artefacta), but hematidrosis cannot be ruled out totally (33). Finally, some of the included cases are in doubt due to a lack of precision and insufficient investigation (22, 28, 29).

The physiopathology of hematidrosis is largely unknown. Skin biopsies fail to find any convincing organic anomalies. The activation of the sympathetic nervous system or local vascular permeability due to psychological stress or neurological activities may be involved (24). This would explain the beneficial effects of betablockers, anxiolytics, and psychotherapy.

\section{Conclusion}

Even though the physiopathology of hematidrosis is still unclear, it can be considered a somatization disorder that mainly affects young children in developing countries. It can have a non-negligible impact on the life of the patients. It is of outmost importance to rule out any other differential diagnoses, such as a bleeding disorder, chromhidrosis, or self-inflicted skin lesions, and to identify this condition. The medical staff should attend and confirm de visu at least one bleeding episode. Biochemical or cytology analysis should also confirm the bloody nature of the fluid. Management includes beta-blockers, anxiolytic drugs, and psychological support. The benign and transient nature of the disease should be explained to the parents and the patient. 


\section{References}

1. Kluger N, Cribier B. Stigmata: from Saint-Francis of Assisi to idiopathic haematidrosis. Ann Dermatol Venereol. 2013;140:771-7. French.

2. Early LF, Lifschutz JE. A case of stigmata. Arch Gen Psychiatry. 1974;30:197-200.

3. Holoubek JE, Holoubek AB. Blood, sweat and fear. A classification of hematidrosis. J Med. 1996;27:115-33.

4. Bonamonte D, Vestita M, Filoni A, Giudice G, Angelini G. Religious stigmata as malingering artifact: report of a case and review of the literature. Medicine (Baltimore). 2016;95:e5354.

5. Del Forno C. Stigmata: from Saint Francis of Assisi to idiopathic hematidrosis. Ann Dermatol Venereol. 2014;141:529-30. French.

6. Zhang FK, Zheng YL, Liu JH, Chen HS, Liu SH, Xu MQ, et al. Clinical and laboratory study of a case of hematidrosis. Zhonghua Xue Ye Xue Za Zhi. 2004;25:147-50. Chinese.

7. Wang LJ, An CX, Li YM, Cao CQ. A case report of childhood hematidrosis. Zhongguo Dang Dai Er Ke Za Zhi. 2014;16:214-5. Chinese.

8. Manonukul J, Wisuthsarewong W, Chantorn R, Vongirad A, Omeapinyan P. Hematidrosis: a pathologic process or stigmata. A case report with comprehensive histopathologic and immunoperoxidase studies. Am J Dermatopathol. 2008; 30:135-9.

9. Carvalho AC, Machado-Pinto J, Nogueira GC, Almeida LM, Nunes MB. Hematidrosis: a case report and review of the literature. Int J Dermatol. 2008;47:1058-9.

10. Bhagwat PV, Tophakhane RS, Rathod RM, Shashikumar BM, Naidu V. Hematohidrosis. Indian J Dermatol Venereol Leprol. 2009;75:317-8.

11. Jerajani HR, Jaju B, Phiske MM, Lade N. Hematohidrosis-a rare clinical phenomenon. Indian J Dermatol. 2009;54:290-2.

12. Mishra KL. Bloody tears and hematohidrosis in a patient of $\mathrm{PF}_{3}$ dysfunction: $\mathrm{a}$ case report. Cases J. 2009;2:9029.

13. Patel RM, Mahajan S. Hematohidrosis: A rare clinical entity. Indian Dermatol Online J. 2010;1:30-2.

14. Wang Z, Yu Z, Su J, Cao L, Zhao X, Bai X, et al. A case of hematidrosis successfully treated with propranolol. Am J Clin Dermatol. 2010;11:440-3.

15. Praveen BK, Vincent J. Hematidrosis and hemolacria: a case report. Indian J Pediatr. 2012;79:109-11.

16. Latorre Martinez N, Betlloch Mas I, Monteagudo Paz AF, Lucas Boronat J. Recurrent bleeding in an 18-year-old girl. Arch Dermatol. 2012;148:960-1.

17. Mora E, Lucas J. Hematidrosis: blood sweat. Blood. 2013;121:1493.

18. Khalid SR, Maqbool S, Raza N, Mukhtar T, Ikram A, Qureshi S. Ghost spell or hematohidrosis. J Coll Physicians Surg Pak. 2013;23:293-4.
19. Ben Abdallah Chabchoub R, Safi F, Trabelsi L, Maalej B, Gargouri L, Turki F, et al. Hematidrosis in a child. Arch Pediatr. 2013;20:563-4. French.

20. Bhattacharya S, Das MK, Sarkar S, De A. Hematidrosis. Indian Pediatr. 2013;50: 703-4.

21. Biswas S, Surana T, De A, Nag F. A curious case of sweating blood. Indian J Dermatol. 2013;58:478-80.

22. Tshifularo M. Blood otorrhea: blood stained sweaty ear discharges: hematohidrosis; four case series (2001-2013). Am J Otolaryngol. 2014;35:271-3.

23. Deshpande M, Indla V, Kumar V, Reddy IR. Child who presented with hematohidrosis (sweating blood) with oppositional defiant disorder. Indian J Psychiatry. 2014:56:289-91.

24. Shen H, Wang Z, Wu T, Wang J, Ren C, Chen H, et al. Haematidrosis associated with epilepsy in a girl successfully treated with oxcarbazepine: case report. J Int Med Res. 2015;43:263-9.

25. Varalakshmi B, Doshi VV, Sivalingam D, Nambi S. The story of a girl with weeping blood: childhood depression with a rare presentation. Indian J Psychiatry. 2015;57:88-90.

26. Uber M, Robl R, Abagge KT, Carvalho VO, Ehlke PP, Antoniuk SA, et al. Hematohidrosis: insights in the pathophysiology. Int J Dermatol. 2015;54:e542-3.

27. Techasatian L, Waraasawapati S, Jetsrisuparb C, Jetsrisuparb A. Hematidrosis: a report with histological and biochemical documents. Int J Dermatol. 2016;55: 916-8.

28. Rharrabti S, Khattala K, Belahsen M, Aalouane R. Hematidrosis and hemolacrea associated with conversion disorder. About a pediatric case. Presse Med. 2016; 45:712-4. French.

29. Jafar A, Ahmad A. Child who presented with facial hematohidrosis compared with published cases. Case Rep Dermatol Med 2016;2016:5095781.

30. Yeşilova Y, Turan E, Aksoy M. Hematidrosis on the forehead following trauma: a case report. Int J Dermatol. 2017;56:212-4.

31. World Health Organization. International Classification of Diseases (ICD-10) Version:2016 [Internet]. Available at: http://apps.who.int/classifications/icd10/ browse/2016/en. Accessed December 25, 2016.

32. Kotru M, Mutereja D, Purohit A, Tyagi S, Mahapatra M, Saxena R, et al. Mild bleeders: diagnosis is elusive in large number of patients. Mediterr J Hematol Infect Dis. 2016;8:e2016049.

33. Rouxel AM, Roguedas AM, Roussel B, Bettembourg S, Richard Y, Pan-Petesch B, et al. Tears of blood? Eur J Dermatol. 2010;20:232-3. 